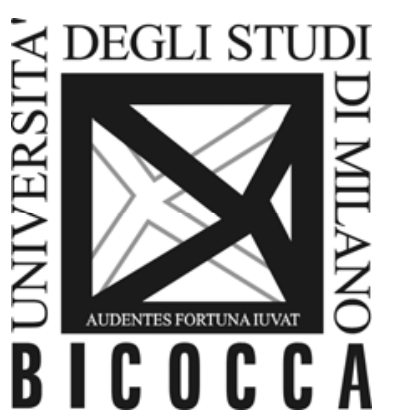

DEPARTMENT OF ECONOMICS,
MANAGEMENT AND STATISTICS
UNIVERSITY OF MILAN - BICOCCA

DEMS WORKING PAPER SERIES

\title{
Measuring the Monetary Value of Social Relations: a Hedonic Approach
}

\author{
Emilio Colombo, Luca Stanca
}

No. 256 - October 2013

Dipartimento di Economia, Metodi Quantitativi e Strategie di Impresa Università degli Studi di Milano - Bicocca http://dems.unimib.it/ 


\title{
Measuring the Monetary Value of Social Relations: a Hedonic Approach*
}

\author{
Emilio Colombo ${ }^{\dagger}$ and Luca Stanca ${ }^{\ddagger}$
}

October 11, 2013

\begin{abstract}
This paper presents an application of the hedonic approach to measure the monetary price of social relations. We use individual-level data for housing and labor markets in 103 Italian cities to estimate the price of relational amenities and construct monetary indexes of quality of relational life. We focus on time spent with friends, active participation in associations and frequency of going out for leisure activities, while controlling for standard amenities such as weather, environment, services, and socio-demographic characteristics. We find that individuals are willing to pay a positive and significant monetary price to live in cities where people spend more time with their friends. A one standard deviation increase in the share of those who meet their friends most frequently is worth an extra $€ 1,150$ per year in terms of higher housing costs and foregone wages.
\end{abstract}

JEL Classification: A13, C4, D6, I31, R2, Z13

Keywords: social relations, social capital, hedonic prices, quality of life, well-being.

*The authors gratefully acknowledge Agenzia del Territorio (Osservatorio del Mercato Immobiliare) and the Statistical Office of Regione Lombardia for granting access to microdata. Financial support by the Italian Ministry of Education is also gratefully acknowledged.

${ }^{\dagger}$ Department of Economics, University of Milan Bicocca. Piazza dell'Ateneo Nuovo 1, 20126 Milan, Italy. E-mail: emilio.colombo@unimib.it

${ }^{\ddagger}$ Corresponding author. Department of Economics, University of Milan Bicocca, Piazza dell'Ateneo Nuovo 1, 20126 Milan, Italy. E-mail: luca.stanca@unimib.it 


\section{Introduction}

Traditionally, economists have adopted a rather narrow view of social interactions. Relevant interactions among agents would take place within markets, and were therefore viewed as fundamentally instrumental and anonymous. Non-market interactions were largely not of interest. This generally resulted in an under-socialised conception of economic action (Granovetter, 1985). More recently, however, the focus of the discipline has changed dramatically, as economists have become increasingly interested in the nature, causes and effects of social interactions (see e.g. Manski, 2000, Gui and Sugden, 2005, Durlauf and Ioannides, 2010).

Two main strands can be identified within the recent economic literature on social interactions. The first has viewed social interactions as a way of facilitating coordinated action, within the broader notion of social capital (Bourdieu, 1986, Coleman, 1990, Putnam, 1993). This strand has thus focused on social connections, in their role as capital goods. ${ }^{1}$ The second, relatively smaller, group of studies has focused on relational goods, defined as interpersonal relations that are characterized by being personalized and non-instrumental (Uhlaner, 1989, Gui and Sugden, 2005). This strand has therefore focused on social relations, in their role as consumption goods. ${ }^{2}$

At the empirical level, a large number of studies have investigated social connections, focusing on rather heterogenous phenomena that can be broadly grouped into the three main dimensions of networks, norms, and trust (Bjørnskov, 2006). Despite the difficulty of clearly defining these concepts, providing an appropriate measurement, and identifying causal effects (Paldam, 2001, Durlauf, 2002, Blume et al., 2011), we do have by now a substantial body of empirical evidence on the economic value of social connections viewed as capital goods (Knack and Keefer, 1997, Moretti 2004). ${ }^{3}$ Conversely, relatively little is known empirically about the economic value of social relations. It is this second aspect, the monetary price of relationships with others viewed as consumption goods, that we focus on in this paper.

\footnotetext{
${ }^{1}$ Putnam (1993, p. 167) defines social capital as " $[. .$.$] features of social organization,$ such as trust, norms, and networks that can improve the efficiency of society by facilitating coordinated actions".

${ }^{2}$ Gui and Sugden (2005, p. 3) define relational goods as "the affective components of interpersonal relations [that] are usually perceived as having value through their sincerity or genuineness".

${ }^{3}$ See also Helliwell, 2006, Bjørnskov, 2003, 2008, and Sarracino, 2010, for recent studies on the effects of social capital on well-being.
} 
Some recent studies have attempted to measure the value of social relations in terms of subjective well-being. Using a large sample of individuals from the World Values Survey, Bruni and Stanca (2008) showed that relational goods have a significant and quantitatively relevant effect on life satisfaction. This effect was indeed found to be stronger for social relations that are personalized and non-instrumental, such as active involvement in charities, church- and art-related volunteering activities, as opposed to unions, parties and environmental organizations. Stanca (2009) used implicit valuations estimated from micro-econometric life satisfaction equations to construct composite indicators of quality of relational life world-wide. Following similar approaches, other authors have used subjective well-being as the metric to estimate the value of social relations, while extending the analysis to different samples and data sets (e.g. Becchetti et al., 2008, 2012, AtecaAmestoy et al., 2013). Overall, these studies suggest that the relational treadmill can provide an additional explanation of the income-happiness paradox: the positive effect of better economic conditions on happiness may be offset by lower consumption of relational goods (Diwan, 2000).

A smaller number of studies have measured the monetary value of social relations using the life satisfaction approach (Frey et al., 2010). Clark and Oswald (2002) estimated the monetary value of life events, showing that, relative to being single, marriage is worth about $\$ 105,000$ a year for a representative individual in the United Kingdom. More recently, Powdthavee (2008) adopted a similar approach to estimate the monetary value of interactions with friends, relatives and neighbours. The findings, based on the British Household Panel Survey, indicate that an increase in the level of social involvement is worth up to $£ 85,000$ a year in terms of life satisfaction. Studies based on the life satisfaction approach, however, only provide an indirect measurement of the monetary value of social relations. They are based on the effects of both social relations and income on life satisfaction. By combining these shadow prices, the monetary value of social relationships can be indirectly estimated. ${ }^{4}$

In this paper we propose an alternative approach, based on hedonic prices, to obtain a direct measurement of the monetary value of social relations. Following Colombo et al. (2012), our framework is based on the spatial equilibrium model of Rosen (1979) and Roback (1982). Households and firms

\footnotetext{
${ }^{4}$ The life satisfaction approach has been used to measure the economic value of several other non-market goods, such as aircraft noise (Van Praag and Baarsma, 2005), fear of crime (Moore and Shepherd, 2006) or terrorism (Frey et al., 2009).
} 
compete to locate in areas characterized by different levels of amenities and dis-amenities. In equilibrium, households are willing to pay higher housing prices and accept lower wages to locate in cities characterized by better amenities. Monetary valuations of local amenities can therefore be obtained from the marginal response of housing prices and wages to the presence of amenities or dis-amenities. A large number of studies have used the hedonic approach to value amenities such as climate, environment, services, and socio-demographic conditions (see Boyle and Kiel, 2001, Palmquist, 1999, Blomquist, 2007, for comprehensive reviews). The present work is, to the best of our knowledge, the first application of the hedonic approach to value relational amenities.

We use micro-level data for housing and labor markets to estimate the monetary price of social relations and construct a monetary index of quality of relational life for 103 Italian cities. We focus on three indicators of social relations: time spent with friends, active participation in associations and frequency of going out for leisure activities. We find that households are willing to pay a positive and significant monetary price to live in cities where people spend more time with their friends. We then use the estimated amenity prices to construct a monetary index of quality of relational life and compare it with other dimensions of overall quality of life. Finally, we examine the relationship between quality of life and subjective well-being, in order to assess the consistency between objective and subjective measures of well-being.

The rest paper is structured as follows. Sections 2 and 3 describe the data and methods, respectively. Section 4 presents the results. Section 5 concludes with a discussion of the main findings and implications of the analysis.

\section{Data}

Our analysis is based on four different micro-level data sets covering 103 Italian provinces on an annual basis between 2001 and 2010. We focus on cities defined as the municipalities of province capitals. Two data sets provide information on social relations and local amenities, respectively. Two additional data sets provide information on the housing market (house prices and characteristics) and the labor market (wages and workers-firms characteristics).

Individual-level information about social relations is obtained from the survey "Aspects of daily life", conducted annually by the Italian Statistical 
Office (ISTAT, 2010) on a rotating sample of about 19,000 households $(50,000$ individuals) per year. This survey, which is part of the Multipurpose integrated system of social surveys, investigates several aspects of the daily life of individuals and families, ranging from family relations to household characteristics, health and lifestyle. We consider six annual waves, from 2005 to 2010, and measure social relations by focusing on three domains: time spent with friends, active participation in associations, and frequency of going out for leisure activities. Table 1 presents descriptive statistics for the relational indicators at individual level. ${ }^{5}$

Table 1: Descriptive statistics, social relations (individual level)

\begin{tabular}{lccccc}
\hline \multicolumn{1}{c}{ Variable } & Mean & Std. Dev. & Min. & Max. & $\mathbf{N}$ \\
\hline Time spent with friends & 3.2 & 1.5 & 0 & 5 & 71870 \\
Active part. in associations & & & & & \\
$\quad$ Volunteering & 0.1 & 0.3 & 0 & 1 & 64997 \\
Non-volunteering & 0 & 0.2 & 0 & 1 & 64941 \\
Party & 0 & 0.1 & 0 & 1 & 65005 \\
Trade union & 0 & 0.1 & 0 & 1 & 64986 \\
& & & & & \\
Frequency of going out & & & & & \\
Theatre & 1.4 & 0.7 & 1 & 5 & 70312 \\
Cinema & 2 & 1.2 & 1 & 5 & 70425 \\
Museum & 1.5 & 0.8 & 1 & 5 & 70115 \\
Opera & 1.2 & 0.6 & 1 & 5 & 70144 \\
Concert & 1.3 & 0.6 & 1 & 5 & 69963 \\
Sport & 1.5 & 1 & 1 & 5 & 70110 \\
Dance & 1.5 & 1.1 & 1 & 5 & 70246 \\
Art & 1.4 & 0.7 & 1 & 5 & 70258 \\
\hline Note: Source: ISTAT (2010), annual survey "Aspects of daily life", years 2005 to 2010.
\end{tabular}

Regarding time spent with friends we use a single variable derived from the following question in the survey: "How often in your free time do you meet with friends?". The variable takes values from 0 to 5 corresponding to the following categories: never, few times per year, less than 4 times per month, once a week, more than once a week, everyday. We construct the city-

\footnotetext{
${ }^{5}$ The sample covers 102 cities, since the individual-level indicators of social relations are not available for the city of Sondrio.
} 
level amenity level as the fraction of individuals with the highest frequency of meeting friends. The resulting city-level indicator is therefore defined as the share of individuals who meet their friends on a regular basis.

Relationships with others through social involvement are measured by focusing on individuals' participation in associations: volunteering associations, non-volunteering associations, parties and trade unions. More specifically, for each activity a dummy variable records whether the individual has actively participated in the association during the previous 12 months. We then construct the individual-level indicator as a dummy variable equal to one if any of the four dummy variables is equal to one, and obtain the corresponding amenity by taking the city-level average of the individual-level indicator. The resulting city-level indicator is therefore defined as the share of individuals who participate in at least one association. It should be noted that this variable refers to active participation, as opposed to mere membership, and is therefore intended to capture the relational dimension of social interactions rather than the network dimension.

Relationships with others through participation in recreational activities are measured by aggregating 8 variables that measure the frequency of participation in the following leisure activities: theatre, cinema, museums, opera, concerts, sport events, dance, art. Each variable takes values from 1 to 5 corresponding to the following categories: never, 1-3 times per year, 4-6 times per year, 7-12 times per year, more than 12 times per year. We construct the overall indicator at individual level as a dummy variable equal to one if any of the 8 dummy variables is equal to 5 (high frequency), and obtain the corresponding amenity by taking the city-level average of the overall individual indicator. The resulting city-level indicator is therefore the share of individuals who go out more than once per month in at least one of recreational activity.

Figure 1 displays the geographical distribution of the three indicators of relational amenities at city level, while Table 2 provides the corresponding descriptive statistics. The share of those who see their friends most frequently is in a range between 10.7 and 39.9 per cent, and is generally higher in cities located in the South. Conversely, active participation in associations, ranging between 0 and 24.4 per cent, is generally higher in cities located in the North and Center-North. The share of those who go out for recreational activities most frequently, ranging between 3.5 and 25.5 per cent, is generally higher in cities located in Center-North.

Information on local amenities and characteristics for the municipalities of 
Figure 1: Indicators of social relations, by city

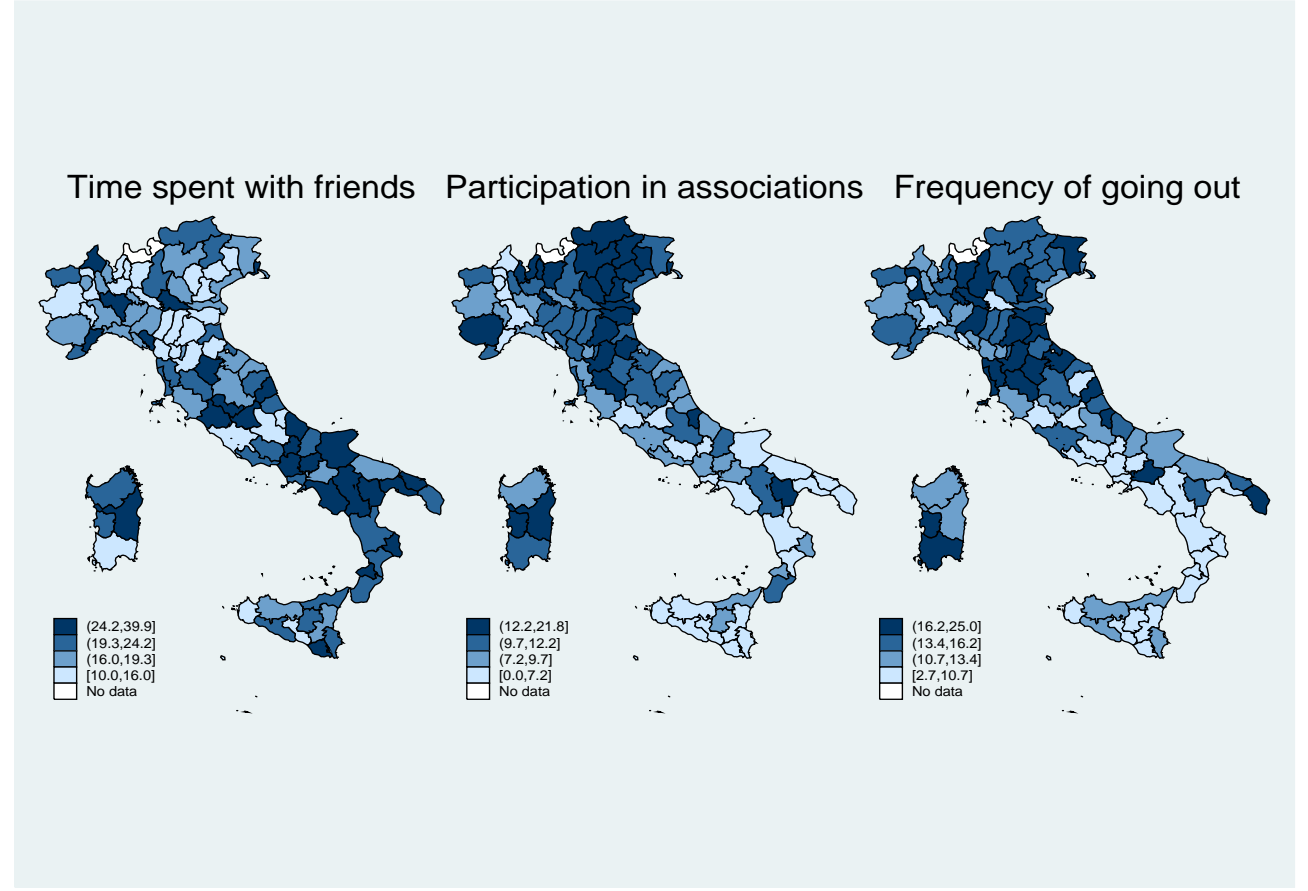

the 103 Italian provinces for the period 2001-2010 has been collected from the Italian National Statistical Office (ISTAT) and other sources (see Colombo et al., 2012, for details and definitions). Summary statistics are provided in Table 2. We focus on 12 city-level amenities (in addition to the three relational amenities described above) that belong to four different domains: climate, environment, services, and society. Climate is measured by maximum temperature in January, precipitation (monthly average) and humidity (maximum in July). The environmental domain is based on both physical features of the territory (percentage of green areas in the city and a dummy variable indicating a coastal city) and pollution (number of air-polluting agents). Indicators for the quality of services focus on education (teacher-pupil ratio), culture (index of cultural infrastructure, capturing several dimensions of the city's cultural offerings, such as museums, cinemas, theatres, etc.), and transport infrastructure (multi-modal indicator of accessibility by air, train and car). The society domain refers to socio-economic conditions of cities, as measured by crime rate, unemployment rate, and population density.

Housing market data are from the Real Estate Observatory of the Agenzia del Territorio, and refer to about 150,000 individual transactions of houses 
Table 2: Descriptive statistics, amenities (city-level)

\begin{tabular}{lccccc}
\hline \hline \multicolumn{1}{c}{ Variable } & Mean & Std. Dev. & Min. & Max. & N \\
\hline Time spent with friends & 20.9 & 6 & 10.7 & 39.9 & 102 \\
Participation in associations & 8.6 & 3.6 & 0 & 20.4 & 102 \\
Frequency of going out & 13.3 & 4.3 & 3.5 & 25.5 & 102 \\
Precipitation & 68.6 & 22.4 & 28.9 & 139.7 & 103 \\
Temperature & 9.1 & 3.7 & 4 & 16 & 103 \\
Humidity & 67.3 & 5.2 & 51 & 77 & 103 \\
Coast & 0.3 & 0.5 & 0 & 1 & 103 \\
Green areas & 6.9 & 11.2 & 0.1 & 71.9 & 103 \\
Air pollution & 7.7 & 2.6 & 1.3 & 15.4 & 103 \\
Teacher-pupil ratio & 9.7 & 0.9 & 8.3 & 13.3 & 103 \\
Transport infrastructure & 91.6 & 24 & 47 & 161 & 103 \\
Cultural infrastructure & 87.3 & 77.6 & 18.9 & 579.2 & 103 \\
Crime rate & 4.1 & 1.5 & 1.1 & 9.9 & 103 \\
Urban density & 1.2 & 1.4 & 0.1 & 8.3 & 103 \\
Unemployment rate & 11.1 & 7.5 & 2.8 & 31.4 & 103 \\
\hline
\end{tabular}

Note: Source: ISTAT and various sources, as detailed in Section 2.

and flats in Italian cities between 2004 and 2010 at semi-annual frequency. In addition to the sale price, the data set provides a detailed description of structural characteristics, such as surface area, age of building, number of bathrooms, floor level, number of garages or car parks, level of maintenance, location (center, semi-center, suburb), quality of building (good, average, bad), and neighborhood characteristics (quality of the area and distance from public services, commercial services and transportation system).

Labour market data are repeated cross-sections of individual workers in the private sector for years 2001 and 2002 from the Italian National Social Security Institute (INPS). The data set provides information on annual earnings, type of occupation, full time or part-time work status, contract length, province of work, and characteristics of workers (gender, age, nationality, province of residence, etc.) and firms (size and sector of activity). We consider all employees aged between 16 and 75, who live in the same city where they work for at least 30 weeks in a year, excluding from the sample seasonal workers. Annual earnings are total yearly wages net of social contributions paid by firms, but gross of social contributions and income taxes paid by workers. 


\section{Methods}

Our analysis is based on the spatial equilibrium model by Rosen (1979) and Roback (1982). Within this framework, households and firms compete to locate in areas characterized by different levels of amenities and dis-amenities. The absence of spatial arbitrage requires that household utility and production costs are equal in equilibrium across cities. Assuming that the supply of housing and the demand for labor are relatively rigid, cross-city differentials in housing costs and wages indicate households' willingness to pay for different amenities. The monetary value of social relations can therefore be estimated by looking at the effects of relational amenities on house price and wage differentials across cities, while controlling for the effects of other relevant amenities, such as climate, environment, services, and socio-economic conditions (see Colombo et al., 2012, for details).

Empirically, we first construct city-level indicators of relational amenities on the basis of individual-level data, as described in Section 2. Then, the implicit prices of relational amenities are estimated from reduced-form equations for housing prices and wages, respectively. The housing-price equation can be written as follows:

$$
\ln p_{h j t}=\beta_{0}+\beta_{1} X_{h j t}+\beta_{2} A_{j}+\beta_{3} R_{j}+\varepsilon_{h j t}
$$

where $p_{h j t}$ denotes the real price, at constant 2004 prices, of housing unit $h$ in city $j$ at time $t, X_{h j t}$ is a vector of housing characteristics (property size, age of building, number of bathrooms, floor level, number of floors, number of lifts, number of garages or car parks, housing type, unit conditions, housing features, value type, location and quality of building) and neighborhood characteristics (location and quality of the area), $A_{j}$ is a vector of standard local amenities in city $j, R_{j}$ is a vector of relational amenities in city $j$, and $\varepsilon_{h j t} \backsim N\left(0, \sigma_{\varepsilon}^{2}\right)$ is the individual-level error term.

The wage equation can be written as follows:

$$
\ln w_{k j t}=\gamma_{0}+\gamma_{1} Z_{k j t}+\gamma_{2} A_{j}+\gamma_{3} R_{j}+\eta_{k j t}
$$

where $w_{k j t}$ is the real wage, at constant 2004 prices, of individual $k$ in city $j$ at time $t, Z_{k j t}$ is a vector of worker-firm characteristics (gender, age, nationality, province of residence, type of occupation, contract length, size of the firm and sector of activity), and $\eta_{k j t} \backsim N\left(0, \sigma_{\eta}^{2}\right)$ is the individual-level error term. 
We control for city-level unobserved heterogeneity by including among regressors population size, income per-capita and a dummy for regional capitals. Year dummies are also included in order to account for individualinvariant time fixed effects. Equations (1) and (2) are estimated by OLS. In order to allow for correlation among individual observations within cities, standard errors are clustered at city-level.

Estimation of the implicit prices from equations (1) and (2) allows us to construct indices of urban quality of life as weighted sums of differenct amenities, where the weights are based on households' revealed preferences. In order to obtain the full implicit price of each amenity the estimated coefficients in equations (1) and (2) are converted into annual household expenditures. The coefficients of the housing equation, evaluated at the mean housing price, are converted into imputed annual rents by applying a 7.85 per cent discount rate, as in Blomquist et al. (1988). The coefficients of the wage equation, evaluated at the mean wage, are multiplied by 1.64, the average number of workers per household (Bank of Italy, 2008). Full implicit prices, obtained as the difference between the implicit shadow price from the housing equation and the one from the wage equation, are multiplied by the value of each amenity in each city $j$, relative to the overall mean, in order to obtain QoL indices for the 103 Italian provinces. The QoL indices thus constructed can be interpreted as the monetary value, at constant 2004 prices, that the representative household attributes to the bundle of amenities available in each city.

\section{Results}

This section presents the results of the empirical analysis. We start by describing the implicit prices of amenities estimated at individual level. We then present a monetary index of quality of relational life at city level. Finally, we examine the relationship between quality of relational life and subjective well-being.

\subsection{The Monetary Price of Social Relations}

Table 3 reports estimation results for equations (1) and (2) based on approximately 151,000 and 157,000 observations, respectively. The model for the housing market data (column 1) explains 72 per cent of the variability of log-housing prices. Focusing on relational amenities, all three coefficients 
are positive, as expected. A one-point increase in the percentage of individuals with high frequency of meetings with friends is associated to a 1.1 per cent increase in real house prices, and the coefficient is strongly statistically significant $(p<0.02)$. A one-point increase in the percentage of individuals who participate actively in volunteering activities and with a high frequency of going out is associated to an increase in real house prices of 0.5 and 0.1 per cent, respectively, although these effects are not statistically significant.

Turning to non-relational amenities, the estimated coefficients generally have the expected sign. Controlling for structural and neighborhood characteristics, housing prices are higher in cities with higher temperature, lower humidity and lower average precipitations, in cities located on the coast, with less pollution and more green areas, in cities with higher teacher-pupil ratio, better transport and cultural infrastructure, and in cities with lower crime and unemployment rates and higher population density. Overall, more than half of the amenity coefficients are statistically significant.

In the wage equation (column 2), the model explains 60 per cent of the variability of log-wages. Two thirds of the estimated coefficients in the wage equation have the same sign as in the housing equation, implying implicit prices with opposite signs. Both time spent with friends and active participation in volunteering are priced as dis-amenities, while the frequency of going out for recreational activities is priced as an amenity. Implicit prices with counter-intuitive signs are also observed for several non-relational amenities. These findings can be interpreted as an indication that local amenities affect the location decisions of both households and firms, so that the net effect on wages of the presence of local amenities is ambiguous. ${ }^{6}$ Nevertheless, the coefficients for city-level amenities are substantially smaller than the ones for the housing price equation, so that the overall estimated prices are generally not affected.

Table 4 reports the estimated full implicit prices of local amenities. These can be interpreted as the monetary amounts, expressed in euros at constant 2004 prices, that households would be willing to pay annually for a oneunit change in the corresponding amenity. For example, the housing price component for time spent with friends (column 1) indicates that households are willing to pay $€ 193.6$ per year for a $1 \%$ increase in the share of those who

\footnotetext{
${ }^{6}$ An alternative possible explanation is the high degree of centralization of the Italian labor market, where wages are regulated by nation-wide contracts that limit regional wage differences for a given occupation. This implies that wages may not fully adjust to compensate for differences in amenities across cities.
} 
Table 3: Implicit prices of amenities, Housing and Labor Markets

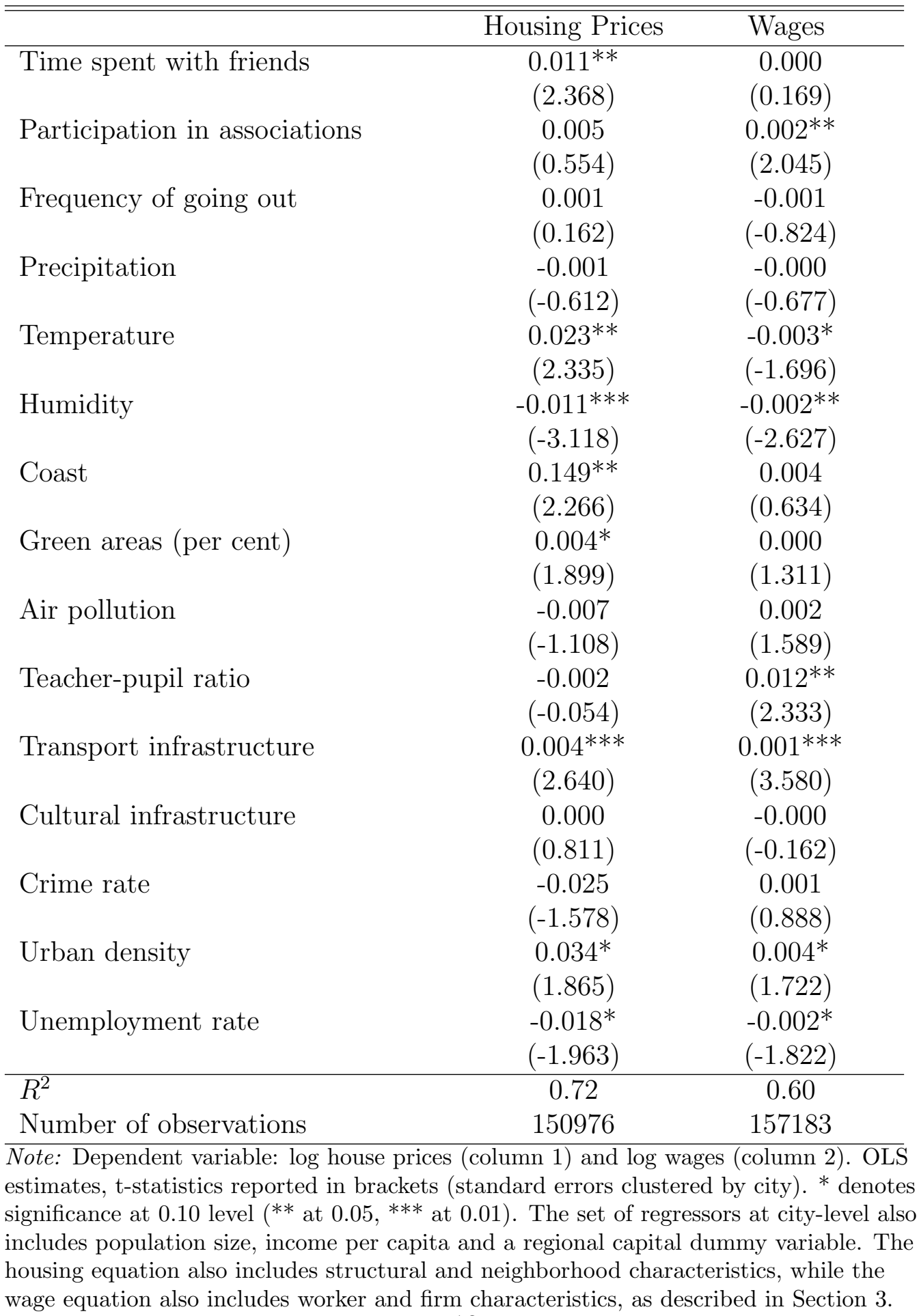


meet with friends most frequently. The wage-equation implicit price (column 2 ) is negative but very small (€-3.5), so that the full implicit price (column $3)$ is $€ 190.1$. This indicates that the representative household is willing to pay 190.1 Euro per year, in terms of higher housing costs and lower wages, for a one per cent increase in the city-level percentage of people who meet their friends more frequently.

Table 4: Full implicit prices of amenities (euro per year)

\begin{tabular}{lcccc}
\hline \hline & House Prices & Wages & Total & QoLI change \\
\hline Time spent with friends & 193.6 & -3.5 & 190.1 & 1147.6 \\
Participation in associations & 79.8 & -64.3 & 15.5 & 61.8 \\
Frequency of going out & 22.7 & 19.3 & 42.0 & 184.8 \\
Precipitation & -17.4 & 3.1 & -14.3 & -319.2 \\
Temperature & 406.7 & 86.1 & 492.8 & 1807.1 \\
Humidity & -187.2 & 57.8 & -129.4 & -676.7 \\
Coast & 2583.4 & -119.6 & 2463.8 & 1172.7 \\
Green areas & 64.0 & -10.5 & 53.5 & 600.4 \\
Air pollution & -123.1 & -46.2 & -169.3 & -442.9 \\
Teacher Pupil Ratio & -33.0 & -353.9 & -386.8 & -350.7 \\
Transport & 68.3 & -17.0 & 51.3 & 1234.4 \\
Cultural infrastructure & 4.2 & 0.2 & 4.4 & 337.7 \\
Crime rate & -429.5 & -43.7 & -473.2 & -687.8 \\
Urban density & 591.1 & -117.8 & 473.3 & 653.6 \\
Unemployment rate & -309.4 & 56.3 & -253.1 & -1892.2 \\
\hline Note: The figus
\end{tabular}

Note: The figures reported are the compensating differentials, expressed in euros at constant 2004 prices, of a one unit change in the corresponding amenity, based on the estimates in Table 3. Quality of life index (QoLI) changes (column 4) are the monetary changes in quality of life associated with a one standard deviation change in the corresponding amenity.

The comparison between columns 1 and 2 in Table 4 shows that the implicit prices from the housing equation are generally substantially larger than those from the wage equation. As a result, with the only exception of the teacher-pupil ratio, all the full implicit prices, reported in column 3, have the expected sign: beneficial amenities have positive monetary prices (temperature in January, coastal location, green areas, transport and culture infrastructure, urban density), while the opposite holds for disamenities (precipitation, humidity, air pollution, crime and unemployment). 
The implicit prices reported in Table 4 are not directly comparable across amenities, as they correspond to variables that are measured in different units. In order to provide a comparison of the size of the effects of different amenities, column 4 in Table 4 reports the change in the monetary index of quality of life associated with a one-standard deviation change in the corresponding amenity. The results indicate that, among the disamenities, unemployment has the largest negative effect on quality of life (about $€ 1,900$ per year), followed by violent crime (€-687.8) and air pollution (€442.9). Among the amenities, the largest effects on quality of life are found for temperature $(€ 1,807)$, transport infrastructure $(€ 1,234)$ and coastal location $(€ 1,172)$. Interestingly, the effect of time spent with friends is not only statistically significant, but also quantitatively relevant, as the corresponding full QoLI change is about $€ 1,150$.

\subsection{A Monetary Index of Quality of Relational Life}

A monetary index of quality of relational life (QoRL) for Italian cities is obtained by multiplying the value of each relational amenity in each city $j$ by the corresponding full implicit prices. In order to obtain normalization, city-level amenities are calculated as deviations from the overall mean. Figure 2 displays the results. Overall, quality of relational life is generally higher in cities of the Center and South, although the pattern is not uniform across space.

Table 5 reports the QoRL city-ranking based on the full implicit prices. The index is normalized with respect to the country average and it can be interpreted as the amount, in 2004 euros, that a representative household would be willing to pay to live in a city with a corresponding bundle of relational amenities, relative to a city with the average set of amenities. The results indicate that relational variables account for substantial variation in quality of life. The city with the highest score is Ascoli Piceno, located in central Italy, with an index value of 3,880. Thus, on average, households would be willing to pay 3,880 euros for living in a city with a corresponding set of relational amenities, relative to a city with average levels of relational amenities. This is a considerable compensating differential, when compared with an average household annual real wage of approximately 30,000 euros in our sample. Negative values can be interpreted as the monetary price that households would want to receive in order to be compensated for living in a city with bad quality of relational life. Overall, large cities tend to display 
Figure 2: Monetary index of quality of relational life

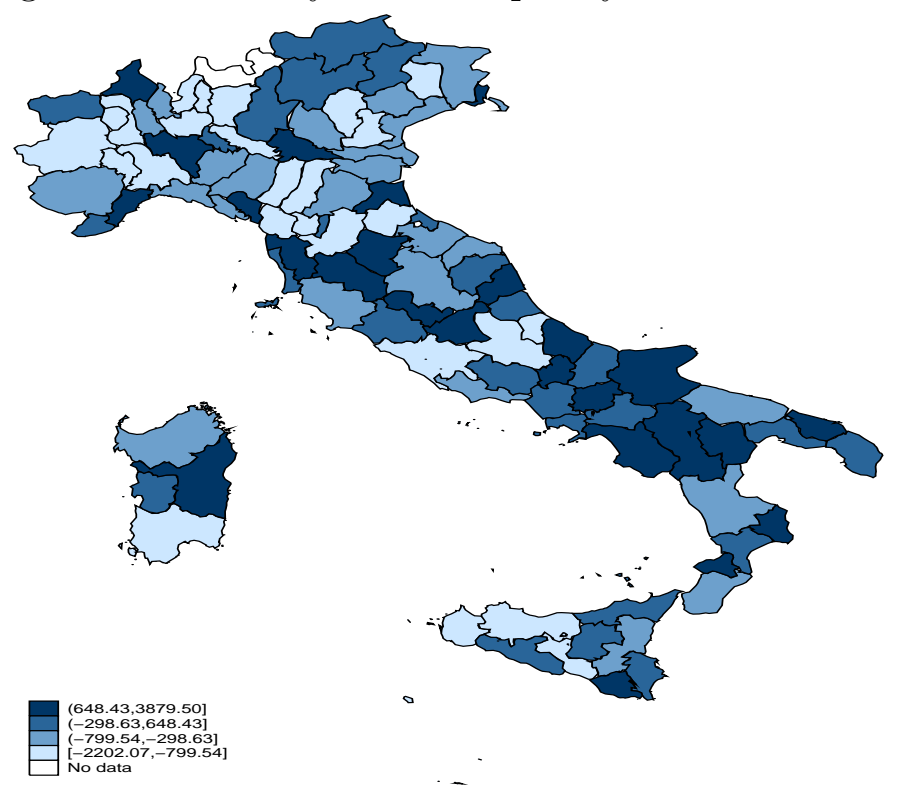

lower values of the QoRL index. Rome, the largest city in Italy, is ranked almost at the bottom (99th), and Milan, the second largest city, is ranked 80th. More generally, 5 out of the 10 largest cities are ranked in the bottom part of the ranking (Rome, 99, Florence, 89, Turin, 81, Milan, 80 and Bologna $71)$.

How does quality of relational life compare with the other components of overall QoL? Figure 3 reports the geographical distribution of the five domain-specific quality of life indices, alongside with the overall index. A clear North-South divide can be observed. Cities in the North generally fare better with respect to services and social conditions, while relatively worse with respect to interpersonal relations, weather and environmental conditions. More generally, the QoRL index is positively correlated to weather ( $\rho=0.18, p=0.06)$ and environmental conditions $(\rho=0.12, p=0.23)$ but negatively related to services $(\rho=-0.37, p=0.02)$ and socio-demographic conditions $(\rho=-0.21, p=0.04)$.

Quality of life is higher in cities located in the Center-North, while cities in the South display relatively worse quality of life. This reflects the fact that the overall quality of life index is dominated by the Services and Society components. Quality of life is generally higher in large (Bologna, Firenze, Venezia) or medium-size cities (e.g. Pisa, Trieste, Imperia, Ancona, Siena, 
Table 5: Monetary index of quality of relational life

\begin{tabular}{|c|c|c|c|c|c|c|c|c|}
\hline Rank & City & $\begin{array}{l}\text { Index } \\
\end{array}$ & Rank & $\overline{~ C i t y ~}$ & Index & Rank & $\overline{~ C i t y ~}$ & Index \\
\hline 1 & Ascoli P. & 3879 & 35 & Brescia & 449 & 69 & Catania & -639 \\
\hline 2 & Vibo V. & 3086 & 36 & Imperia & 415 & 70 & Piacenza & -648 \\
\hline 3 & Arezzo & 2469 & 37 & Messina & 396 & 71 & Bologna & -657 \\
\hline 4 & Benevento & 2143 & 38 & Siracusa & 374 & 72 & Varese & -661 \\
\hline 5 & Brindisi & 2076 & 39 & Teramo & 306 & 73 & Ancona & -709 \\
\hline 6 & Pavia & 2013 & 40 & Rimini & 300 & 74 & Ferrara & -747 \\
\hline 7 & Mantova & 1884 & 41 & Catanzaro & 217 & 75 & Treviso & -755 \\
\hline 8 & Potenza & 1828 & 42 & Livorno & 150 & 76 & La Spezia & -762 \\
\hline 9 & Foggia & 1750 & 43 & Belluno & 96 & 77 & Palermo & -800 \\
\hline 10 & Isernia & 1330 & 44 & Agrigento & 74 & 78 & Alessandria & -850 \\
\hline 11 & Massa & 1288 & 45 & Enna & 67 & 79 & Cagliari & -884 \\
\hline 12 & Verbania & 1288 & 46 & Avellino & 56 & 80 & Milano & -887 \\
\hline 13 & Matera & 1267 & 47 & Napoli & 52 & 81 & Torino & -904 \\
\hline 14 & Nuoro & 1144 & 48 & Trento & 34 & 82 & Bergamo & -923 \\
\hline 15 & Siena & 1070 & 49 & Lodi & -86 & 83 & Pescara & -941 \\
\hline 16 & Terni & 993 & 50 & Prato & -243 & 84 & Biella & -993 \\
\hline 17 & Rieti & 992 & 51 & Frosinone & -290 & 85 & Reggio E. & -998 \\
\hline 18 & Pisa & 978 & 52 & Sassari & -307 & 86 & Pordenone & -1004 \\
\hline 19 & Salerno & 936 & 53 & Reggio C. & -318 & 87 & Pistoia & -1018 \\
\hline 20 & Ravenna & 898 & 54 & Cuneo & -322 & 88 & Lecco & -1076 \\
\hline 21 & Gorizia & 881 & 55 & Perugia & -345 & 89 & Firenze & -1124 \\
\hline 22 & Savona & 766 & 56 & Latina & -350 & 90 & Vicenza & -1138 \\
\hline 23 & Ragusa & 751 & 57 & Grosseto & -368 & 91 & Vercelli & -1153 \\
\hline 24 & Chieti & 726 & 58 & Novara & -391 & 92 & Lucca & -1187 \\
\hline 25 & Crotone & 724 & 59 & Trieste & -427 & 93 & Trapani & -1255 \\
\hline 26 & Oristano & 648 & 60 & Rovigo & -466 & 94 & Forli & -1340 \\
\hline 27 & Lecce & 637 & 61 & Udine & -485 & 95 & L'Aquila & -1365 \\
\hline 28 & Viterbo & 611 & 62 & Parma & -505 & 96 & Cremona & -1402 \\
\hline 29 & Bolzano & 602 & 63 & Verona & -522 & 97 & Padova & -1429 \\
\hline 30 & Macerata & 596 & 64 & Bari & -531 & 98 & Asti & -1491 \\
\hline 31 & Caserta & 541 & 65 & Cosenza & -553 & 99 & Roma & -1492 \\
\hline 32 & Campobasso & 504 & 66 & Pesaro & -581 & 100 & Como & -1551 \\
\hline 33 & Taranto & 471 & 67 & Venezia & -602 & 101 & Modena & -1906 \\
\hline 34 & Aosta & 451 & 68 & Genova & -625 & 102 & Caltanissetta & -2202 \\
\hline
\end{tabular}

Note: Source: ISTAT, INPS and Agenzia del Territorio. The figures reported are expressed in constant 2004 euros per year. 
Figure 3: Quality of life indices, by domain and overall

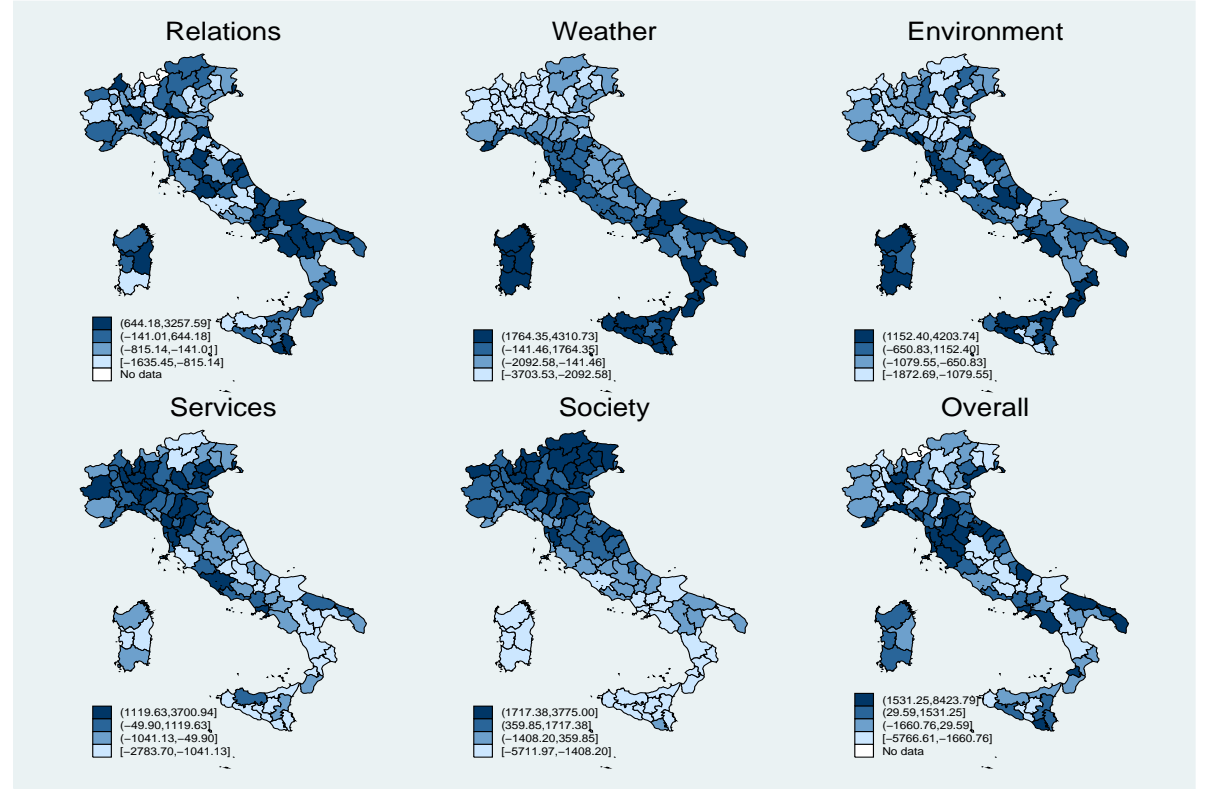

Pesaro, Parma) in the Center-North.

\subsection{Quality of Relational Life and Subjective Well- Being}

The survey "Aspects of daily life" (ISTAT, 2010) provides information about individuals' satisfaction with life, both overall and by individual life domains. In the first case, the question asks the respondent to rate her current degree of satisfaction with life as a whole, in a range between 1 and 10. In the second case, the respondent is asked to rate her satisfaction in the previous year for 7 individual domains of life (economic conditions, health, family relations, relations with friends, use of leisure time, environment and work), using a four-item ordinal scale (very much, enough, not much, not at all). In order to obtain cardinal indicators at city-level, we define highly satisfied with life those individuals who report a life satisfaction level above the overall median (greater than 7). Similarly, we define highly satisfied with a given life domain those individuals who report a domain satisfaction above the overall median (either enough or very much satisfied). We then construct the corresponding city-level shares of individuals with high satisfaction for life overall and for individual life domains. 
Table 6 presents estimation results for cross-city regressions of the high satisfaction indicators described above on the five components of the overall quality of life index described in Section 4.2 (social relations, weather, environment, services and society). Column (1) refers to overall satisfaction with life, while columns (2) to (8) report regression results obtained separately for satisfaction with individual life domains. The estimated coefficients can be interpreted as the percentage change in the share of high satisfaction individuals associated with a $€ 1,000$ change in the corresponding QoL index component. Interestingly, the QoL index for society, that includes crime rate, urban density and unemployment rate, is positively and significantly related to high satisfaction with life (column 1). The coefficients for all other quality of life domains are small and not significantly related to overall life satisfaction.

Table 6: Quality of life and domain-satisfaction

\begin{tabular}{lcccccccc}
\hline \hline & $(1)$ & $(2)$ & $(3)$ & $(4)$ & $(5)$ & $(6)$ & $(7)$ & $(8)$ \\
& Life & Econ & Health & Family & Friends & Leisure & Envir. & Work \\
\hline Relations & -0.13 & 0.86 & $0.49^{*}$ & 0.13 & $1.20^{* *}$ & 1.06 & 0.00 & 0.09 \\
& $(-0.25)$ & $(1.61)$ & $(1.77)$ & $(0.40)$ & $(2.54)$ & $(1.49)$ & $(0.00)$ & $(0.21)$ \\
Weather & 0.10 & -0.48 & -0.17 & -0.44 & -0.35 & -0.31 & -0.14 & 0.25 \\
& $(0.34)$ & $(-1.05)$ & $(-0.67)$ & $(-1.57)$ & $(-0.87)$ & $(-0.57)$ & $(-0.20)$ & $(0.77)$ \\
Environ. & 0.05 & $-0.83^{*}$ & -0.37 & 0.08 & -0.53 & -0.19 & 1.06 & -0.21 \\
& $(0.15)$ & $(-1.81)$ & $(-1.40)$ & $(0.34)$ & $(-1.48)$ & $(-0.34)$ & $(1.39)$ & $(-0.64)$ \\
Services & -0.17 & 0.07 & 0.29 & -0.19 & -0.63 & 0.04 & $-4.18^{* * *}$ & -0.36 \\
& $(-0.52)$ & $(0.17)$ & $(1.25)$ & $(-0.72)$ & $(-1.50)$ & $(0.07)$ & $(-4.85)$ & $(-1.08)$ \\
Society & $0.74^{* *}$ & $3.25^{* * *}$ & $1.10^{* * *}$ & 0.13 & $1.02^{* *}$ & $1.61^{* * *}$ & $4.31^{* * *}$ & $1.81^{* * *}$ \\
& $(2.37)$ & $(6.78)$ & $(3.15)$ & $(0.40)$ & $(2.31)$ & $(3.01)$ & $(5.39)$ & $(4.83)$ \\
\hline$R^{2}$ & 0.06 & 0.69 & 0.45 & 0.08 & 0.29 & 0.28 & 0.37 & 0.37 \\
N. & 102 & 102 & 102 & 102 & 102 & 102 & 102 & 102 \\
\hline
\end{tabular}

Note: OLS estimates, t-statistics in brackets (robust standard errors clustered by city). * denotes significance at 0.10 level $\left(* *\right.$ at $0.05,{ }^{* * *}$ at 0.01$)$.

A similar pattern can be observed for satisfaction with individual life domains, as the society index has in all cases a positive and significant coefficient, with some important qualifications. First, satisfaction with the environment is significantly lower in cities where the quality of services is higher. Second, satisfaction with economic conditions is lower where the quality of the environment is higher. Third, the quality of relational life in- 
dex is positively and significantly associated to satisfaction with health and, most importantly, to satisfaction with relations with friends. In terms of size, a $€ 1,000$ increase in the quality of relational life index is associated to a 1.2 percentage increase in the share of those who are highly satisfied with their relations with friends.

\section{Conclusions}

This paper presented estimates of the monetary value of social relations based on the hedonic approach. We used micro-level data for housing and labor markets, together with city-level data on local amenities, to estimate compensating differentials for three city-level indicators of social relations: time spent with friends, active participation in associations and frequency of going out for leisure activities. Our findings indicate that, controlling for standard amenities such as weather, environment, services, and socio-demographic characteristics, households are willing to pay a positive and significant monetary price to live in cities where people spend more time with their friends. More specifically, a one-standard deviation increase in the number of those who meet with friends more frequently is worth about $€ 1,150$ a year in terms of higher housing costs and foregone wages. In terms of size, the monetary price of social relations is comparable to that of other relevant environmental and socio-economic amenities. This is an interesting finding, as the high monetary value attributed to social relations may contribute to explain the low geographical mobility of Italian households.

We then used the estimated amenity prices to construct a monetary index of quality of relational life in Italian cities. We found a geographical pattern that is very different from the one observed for other components of overall quality of life. Quality of relational life is highest in small-medium cities of the Center-South and is positively related to climatic and environmental conditions. Quality of relational life is instead negatively related to indices of quality of services and socio-demographic conditions. This pattern is consistent with the theory of social capital as a substitute for state failure (Durlauf and Fafchamps, 2005; Woolcock 1998). In cities of the South of Italy, where the provision of services and the quality of society is deficient, interpersonal relations, in addition to weather and environment, compensate for these failures. However, this offsetting effect is only partial, as the overall quality of life index is higher in large and medium-sized cities of the Center-North, reflecting better services and socio-economic conditions. 
Finally, we assessed the consistency between objective and subjective measures of well-being, an issue that is particularly relevant for policymakers. More specifically, we examined the relationship between quality of life and subjective well-being across Italian cities. The key finding is that both overall satisfaction with life and satisfaction with individual life domains are strongly related to the socio-economic component of quality of life. We also find that subjective satisfaction with friends is positively and significantly associated to the objective indicator of quality of relational life. This is an important result, as it provides a confirmation of the consistency between objective and subjective measures of relational well-being, while extending to the social relations domain the findings recently reported by Oswald and $\mathrm{Wu}$ (2010) for overall quality of life. 


\section{References}

Ateca-Amestoy, V., Aguilar, A., Moro-Egido, A. (2013), Social Interactions and Life Satisfaction: Evidence from Latin America. Journal of Happiness Studies, 108(3), 453-490.

Becchetti, L., Pelloni, A., Rossetti, F., 2008. Relational Goods, Sociability, and Happiness. Kyklos, 61, 343-363.

Becchetti, L., Giachin Ricca, E., Pelloni, A., 2012. The Relationship Between Social Leisure and Life Satisfaction: Causality and Policy Implications, Social Indicators Research, 108(3), 453-490.

Bjørnskov, C., 2003. The happy few: Cross-country evidence on social capital and life satisfaction. Kyklos, 56(1), 3-16.

Bjørnskov, C., 2006. The multiple facets of social capital. European Journal of Political Economy, 22, 22-40.

Bjørnskov, C., 2008. Social capital and happiness in the United States. Applied Research Quality Life, 3, 4362.

Blomquist, G., 2007. Measuring Quality of Life, in Arnott, R. and McMillen, D., Eds., A Companion to Urban Economics, Oxford: Blackwell-Synergy, 483-501.

Blume, L.E., Brock, W.A., Durlauf, S.N., Ioannides, Y.M., 2011. Identification of social interactions, Handbook of Social Economics, 1(1), 853-964.

Bourdieu, P., 1986. The forms of capital. In J. Richardson (Ed.), Handbook of theory and research for the sociology of education. New Cork: Greenwood Press.

Boyle, M.A., Kiel, K.A., 2001. A survey of house price hedonic studies of the impact of environmental externalities. Journal of Real Estate Literature, 9, 117144.

Bruni, L., Stanca, L., 2008. Watching alone: Relational Goods, Television and Happiness, Journal of Economic Behavior and Organization, 65(3), 506-528. 
Coleman, J., 1990. Foundations of social theory. Cambridge, MA: Belknap Press of Harvard University Press.

Clark A., Oswald, A., 2002. A simple statistical method for measuring how life events affect happiness, International Journal of Epidemiology, 31(6), 1139-1144.

Colombo, E., Michelangeli, A., Stanca, L., 2012. "La Dolce Vita: Hedonic Estimates of Quality of Life in Italian Cities" Regional Studies, forthcoming, doi: 10.1080/00343404.2012.712206.

Diwan, R., 2000. Relational wealth and the quality of life, Journal of SocioEconomics, 28, 305-340.

Durlauf, S.N., 2002. On the empirics of social capital. The Economic Journal, 112, 459479.

Durlauf, S., Fafchamps, M., 2005. Social Capital, in Aghion P., Durlauf S. (eds.), Handbook of Economic Growth, 1(26), 1639-1699 Elsevier.

Durlauf, S.N., Ioannides, Y., 2010. Social Interactions, Annual Review of Economics, 2, 451-478

Frey, B.S., Luechinger, S., Stutzer, A., 2010. The Life Satisfaction Approach to Environmental Valuation, Annual Review of Resource Economics, Annual Reviews, 2 (1), 139-160.

Frey, B.S., Luechinger, S., Stutzer, A., 2009. The life satisfaction approach to valuing public goods: The case of terrorism, Public Choice, Springer, 138(3), 317-345.

Granovetter, M. (1985). Economic action and social structure: the problem of embeddedness, American Journal of Sociology, 91(3), 481510.

Gui, B., Sugden, R. (2005) "Why Interpersonal Relations Matter for Economics", in: Gui and Sugden (eds.), Economics and Social Interactions, Accounting for Interpersonal Relations. Cambridge (Mass.): Cambridge University Press: 1-22.

Helliwell, J. F. (2006). Well-being, social capital and public policy: Whats new? The Economic Journal, 116, 3445. 
ISTAT, 2010. La vita quotidiana nel 2008 - Indagine multiscopo annuale sulle famiglie, Aspetti della vita quotidiana, Rome.

Knack, P., Keefer, S., 1997. Does social capital have an economic payoff? A cross-country investigation, Quarterly Journal of Economics, 107, 12521288

Manski, C., 2000. Economic Analysis of Social Interactions, Journal of Economic Perspectives, 14(3), 115136.

Moore, S.C., Shepherd, J.P., 2006. The cost of fear: shadow pricing the intangible costs of crime. Applied Economics 38(3), 293-300.

Moretti E. (2004) Human Capital Externalities in Cities, in Henderson V., Thisse J-F., Handbook of Regional and Urban Economics, Elsevier.

Oswald, A., Wu, S. 2010. Objective confirmation of subjective measures of human well-being: evidence from the USA. Science, 327(5965), 576579.

Paldam, M., (2001) "Social Capital: One Or Many? Definition And Measurement", Journal of Economic Surveys, 14, 5, 629-653.

Palmquist, R.B., 1999. ,Hedonic Models, In J.C.J.M van den Bergh (Eds.), Handbook of Environmental and Resource Economics. Cheltenham: Edward Elgar, 765-776.

Powdthavee, N., 2008. Putting a Price Tag on Friends, Relatives, and Neighbours: Using Surveys of Life-Satisfaction to Value Social Relationships, Journal of Socio-Economics, 37(4), 1459-1480.

Putnam, R.D., 1993. Making democracy work: Civic traditions in modern Italy. Princeton, NJ: Princeton University Press.

Roback, J., 1982. Wages, Rents, and the Quality of Life, Journal of Political Economy, 90(6), 1257-78.

Rosen, S., 1979. Wage-based indexes of urban quality of life, 74-104, in P. Mieszkowsi and M. Stratzheim (eds.) Current issues in urban economics, John Hopkins Press, Baltimore.

Sarracino, F., 2010. Social capital and subjective well-being trends: Comparing 11 western European countries. The Journal of Socio-Economics, $39,482517$. 
Stanca, L., 2009, "With or Without You: Measuring the Quality of Relational Life Throughout the World, Journal of Socio-Economics, 38, 834-842.

Uhlaner, C.J., 1989. Relational goods and participation: incorporating sociality into a theory of rational action. Public Choice 62, 253-285.

Van Praag, B., Baarsma, B., 2005. Using Happiness Surveys to Value Intangibles: The Case of Airport Noise, The Economic Journal, 115, 224-246.

Woolcock, M., 1998. Social Capital and Economic Development: Toward a Synthesis and Policy Framework. Theory and Society, Vol.27, pp.151208. 